\title{
Fundamental host range of Trissolcus japonicus in Europe
}

\author{
Tim Haye $^{1}\left[\right.$ D Silvia T. Moraglio ${ }^{2} \cdot$ Judith Stahl $^{1} \cdot$ Sara Visentin $^{2} \cdot$ Tommaso Gregorio $^{3} \cdot$ Luciana Tavella $^{2}$
}

Received: 4 March 2019 / Revised: 23 May 2019 / Accepted: 29 May 2019 / Published online: 3 June 2019

(c) The Author(s) 2019

\begin{abstract}
The brown marmorated stink bug, Halyomorpha halys, native to East Asia, is an invasive alien pest that arrived in Europe in the early 2000s and poses an imminent threat to a wide variety of crops. Adventive populations of the Asian egg parasitoid Trissolcus japonicus, the most promising agent for classical biological control of $H$. halys, have recently been detected in Italy and Switzerland. Its prospective fundamental host range in Europe was evaluated in behavioural no-choice tests, followed by large-arena choice tests presenting host plants with naturally laid egg masses of target and non-target hosts. Developmental suitability of European non-target host species for T. japonicus was demonstrated, via no-choice tests, by offspring emergence (successful parasitism) from eleven out of thirteen non-target species tested (85\%). Whereas successful parasitism of most non-target species was significantly lower, acceptance of Arma custos, Palomena prasina, Pentatoma rufipes, and Rhaphigaster nebulosa was not significantly different from $H$. halys controls. When eggs of $H$. halys and non-target species were exposed in a semi-natural situation in large-arena choice tests, the degree of non-target parasitism was substantially reduced for three out of four tested species, whereas parasitism of Pa. prasina eggs was not. It remains unclear if there are behavioural barriers to parasitism that may exist and preclude excessive parasitism of potentially threatened species in the field, but field data from the invaded areas in Switzerland and Italy could contribute to a risk-benefit evaluation of releasing or re-locating adventive T. japonicus populations into other parts of Europe.
\end{abstract}

Keywords Biological control $\cdot$ Egg parasitoids $\cdot$ Non-target effects $\cdot$ Risk assessment $\cdot$ Halyomorpha halys

\section{Key message}

- The Asian egg parasitoid Trissolcus japonicus, the main antagonist of the invasive Halyomorpha halys, was recently discovered in Europe (i.e. Italy and Switzerland).

Communicated by M. Traugott.

Electronic supplementary material The online version of this article (https://doi.org/10.1007/s10340-019-01127-3) contains supplementary material, which is available to authorized users.

Tim Haye

t.haye@cabi.org

1 CABI, Rue Des Grillons 1, 2800 Delemont, Switzerland

2 Dipartimento di Scienze Agrarie, Forestali e Alimentari (DISAFA), Entomologia Generale e Applicata, University of Torino, Largo P. Braccini 2, 10095 Grugliasco, TO, Italy

3 Hazelnuts Company Division, Ferrero Trading Luxembourg, Rue de Trèves, 2632 Findel, Luxembourg
- We investigated its fundamental host range in Europe in behavioural no-choice and large-arena choice experiments.

- In no-choice tests, eleven out of thirteen non-target species were suitable for development and acceptance of four species was not significantly different from $H$. halys.

- In choice tests, non-target parasitism was substantially reduced for three out of four tested species.

- Field data from the invaded areas in Europe could contribute to a risk-benefit evaluation of releasing or relocating adventive T. japonicus populations.

\section{Introduction}

The brown marmorated stink bug, Halyomorpha halys (Stål) (Hemiptera: Pentatomidae), native to East Asia (China, Taiwan, Japan, and Korea), is an invasive alien pest that poses an imminent and serious threat to a wide variety of tree fruit, nut, vegetable, and field crops in Europe, due to its polyphagous behaviour (Leskey and Nielsen 2018). Invasive 
populations of $H$. halys were first detected in North America and Europe in the 1990s and 2000s, respectively (Hoebeke and Carter 2003; Haye et al. 2015a), and since its arrival in Europe, it has spread to 27 countries (Claerebout et al. 2018). Economic damage to agricultural crops occurs five to 10 years after establishing in locations where the pest is univoltine, whereas severe damage is often observed in less than 5 years after establishing in locations where the pest is bivoltine (e.g., Italy, Republic of Georgia). In the latter regions, it has had a particularly devastating economic impact in tree fruit (e.g., apples, peaches, pears), and nuts (hazelnuts) (Maistrello et al. 2017; Bosco et al. 2018). If spring and summer temperatures continue to increase due to climate change, $H$. halys has the potential to further expand its range throughout Europe (Kriticos et al. 2017) and become bivoltine in regions where it used to be univoltine, as observed in north-western Switzerland in 2018 (Haye, personal observation).

To date, the management of $H$. halys in Europe still relies on the application of broad-spectrum insecticides, but more environmentally friendly and self-sustaining control measures, such as biological control, are urgently needed for an area-wide control (Haye et al. 2015a). Native European egg parasitoids, such as Anastatus bifasciatus (Geoffroy) (Hymenoptera: Eupelmidae) and Ooencyrtus telenomicida (Vassiliev) (Hymenoptera: Encyrtidae) can successfully develop on viable eggs of $H$. halys (Haye et al. 2015b; Roversi et al. 2016; Stahl et al. 2018), but their impact following inundative mass releases is currently considered insufficient to effectively suppress the pest. Other native European egg parasitoids in the genera Trissolcus Ashmead and Telenomus Haliday (Hymenoptera: Scelionidae) have been reported to oviposit in $H$. halys eggs, but their offspring are unable to develop on the exotic host (Haye et al. 2015b; Abram et al. 2017).

Whereas the impact of native natural enemies on invasive H. halys populations in Europe and North America is generally low (Abram et al. 2017; Costi et al. 2018), classical biological control using native natural enemies from the pest's origin seems to be more promising. In Asia, H. halys is attacked by more than ten species of parasitoids, mostly egg parasitoids, among which Trissolcus japonicus (Ashmead) (Hymenoptera: Scelionidae) was identified as the most promising biocontrol candidate, with reported parasitism levels ranging from 50 to 90\% (Yang et al. 2009; Lee et al. 2013; Zhang et al. 2017). Its natural geographic range comprises Japan, China, Taiwan, and South Korea, but adventive populations have been discovered in the eastern and western USA (Talamas et al. 2015; Milnes et al. 2016; Hedstrom et al. 2017), and more recently, in Canada (Abram et al. 2019a), southern Switzerland (Stahl et al. 2018), and northern Italy (Sabbatini Peverieri et al. 2018). Bioclimatic envelope models suggest that $T$. japonicus will follow its host $H$. halys, spreading naturally throughout Europe with the most suitable regions located in northern Italy, Georgia, northern Turkey, south-western France, Catalonia, and Croatia (Avila and Charles 2018).

In many countries, regulatory requirements have become more proscriptive, and approval for release of any classical biological control agent is based on a thorough risk assessment determined from a petition providing detailed information on the biology and ecology of the agent, and particularly its host range (Hunt et al. 2008). Ecological risk assessment in classical biological control estimates the likelihood that negative effects, such as the reduction of non-target populations, will occur after releases as well as the dimension and consequences of these effects (Heimpel and Mills 2017). The likelihood of potential negative effects is usually evaluated in a series of laboratory host specificity tests in which target versus non-target parasitism is compared under choice or no-choice conditions (van Lenteren et al. 2006). In the case of T. japonicus, previous laboratory host range studies on stink bugs in North America (Hedstrom et al. 2017) and from its native range in China (Zhang et al. 2017) indicate that this parasitoid has a broad fundamental host range within the family Pentatomidae. These studies were exclusively performed as black box experiments in small choice arenas, without direct observations of parasitoid behaviour to determine the relationship between levels of acceptance and levels of parasitoid development. In addition, the experiments lacked host findings cues, such as chemical footprints left behind by the stink bugs on plant surfaces and synomones emitted by plants due to oviposition and feeding by the bugs, which play an essential role in host egg location of Trissolcus parasitoids (Colazza et al. 2004, 2007, 2009).

Here, we present results from a thorough study which aimed to assess the prospective fundamental (physiological) host range of $T$. japonicus in Europe. To evaluate target (H. halys) versus non-target parasitism under more realistic conditions than previous laboratory host range studies, we conducted behavioural no-choice tests, followed by large-arena choice tests presenting host plants with naturally laid egg masses of target and non-target hosts (van Lenteren et al. 2006). We use these results to predict the ecological host range and possible non-target impact of $T$. japonicus. These predictions are particularly relevant due to the recent adventive establishment of T. japonicus in two European countries (i.e., Italy and Switzerland) as they provide a unique opportunity to validate estimates of fundamental host range with realized (ecological) 'post arrival' host range as it manifests over time.

\section{Materials and methods}

\section{Selection, source, and rearing of stink bug species}

Non-target species were selected according to the information on $T$. japonicus hosts available from the literature, 
phylogenetic relatedness, and sympatry of target and nontarget species, phenology, safeguard considerations (beneficial species), and availability (Kuhlmann et al. 2006). In total, thirteen species were selected, including eleven pentatomids (same family as the target $H$. halys), one scutellerid and one coreid (outgroup species from different families) (Table 1).

The $H$. halys colony was originally established in 2017 from about 500 individuals collected in Basel, Switzerland. The insects were maintained in groups of 50 individuals in polyester cages (BugDorm-4090 Insect Rearing Cage $47.5 \times 47.5 \times 47.5 \mathrm{~cm}$, MegaView Science Co. Ltd., Taichung, Taiwan) at $26{ }^{\circ} \mathrm{C}, 70 \% \mathrm{RH}$, and a $16 \mathrm{~L} / 8 \mathrm{D}$ photoperiod. Both adults and nymphs were fed with corn, beans, and peanuts that were replaced twice weekly. In winter and spring, bugs were provided with fruit-bearing branches of common ivy (Hedera helix L., Araliaceae) and later in the season with a variety of seasonal plants (e.g., Cornus sanguinea L., Cornaceae and Sorbus aucuparia L., Prunus avium L., Rosaceae).

Overwintered, non-target species (Hemiptera: Pentatomidae, Scutelleridae, Coreidae) were collected from sunexposed house walls in early spring, by visual inspection or plant beating from their host plants (crop and non-crop, herbaceous and arboreous) throughout summers 2017-2018 in Piedmont, NW Italy; the Jura mountains, NW Switzerland; north of Lake Constance, S Germany; Samegrelo, W Georgia (Table 1). Species were identified using the keys by Wyniger and Kment (2010), Derjanschi and Péricart (2005), and Moulet (1995). Non-target stink bugs were reared in the type of cage as used for $H$. halys and kept at $24 \pm 1{ }^{\circ} \mathrm{C}, 60 \%$ $\mathrm{RH}$, and a $16 \mathrm{~L} / 8 \mathrm{D}$ photoperiod. Adults of most species were provided with potted broad bean plants, bramble branches, apples, hazelnuts, and green beans, which were replaced once per week. Adults of Eurygaster maura (L.) were provided with wheat ears instead, and adults of Arma custos (F.) were fed with adults of Plodia interpunctella (Hübner) (Lepidoptera: Pyralidae) or larvae of Tenebrio molitor L. (Coleoptera: Tenebrionidae). Newly laid egg masses of target and non-target species were collected on a daily basis.

\section{Parasitoid rearing}

Trissolcus japonicus were originally collected from $H$. halys eggs near Beijing, China (N40 $02^{\prime} 06^{\prime \prime}$; E116 $\left.12^{\prime} 41^{\prime \prime}\right)$ in 2013, and maintained on fresh H. halys egg masses in the $\mathrm{CABI}$ quarantine facility. Parasitoids (mated, $\geq 2$ days old) were held in a clear plastic container $(10 \mathrm{~cm}$ diameter, $5 \mathrm{~cm}$ height) with $10 \%$ honey water solution as a food source and 8-10 fresh $H$. halys egg masses provided once per week. Parasitized egg masses were kept at $26^{\circ} \mathrm{C}, 60 \%$ $\mathrm{RH}$, and 16L/8D photoperiod. Upon the initial establishment of the laboratory colony, specimens of $T$. japonicus were taxonomically identified by E. Talamas (Systematic Entomology Laboratory, USDA) and confirmed molecularly by M.C. Bon (USDA-ARS-EBCL, Montferrier le Lez, France) (Stahl et al. 2018). Reference specimens are located in the Natural History Museum of Bern, Switzerland.

\section{No-choice tests}

No-choice black box tests performed in China (Zhang et al. 2017) and North America (Hedstrom et al. 2017) indicated that non-target parasitism of European non-target species seems likely, so we conducted no-choice behavioural tests, as suggested by van Lenteren et al. (2006), including direct observations of the parasitoid oviposition behaviour during the time of egg exposure. In contrast to black box tests, this method allowed us to follow the fate of each parasitized egg and relate parasitoid emergence directly to the observed oviposition behaviour of the wasps. The advantage of this method is that false conclusions regarding the parasitoid behaviour can be avoided, which may be drawn if parasitoids have non-reproductive effects on their hosts (Abram et al. 2019b). Such effects may occur when the non-target test list includes species that function as an 'evolutionary trap' (emergence of host nymphs despite parasitoid oviposition) (Abram et al. 2014; Haye et al. 2015b), or die due to parasitism but fail to produce parasitoid offspring (parasitoidinduced host egg abortion, Abram et al. 2016).

Egg masses of $H$. halys and non-target species were collected from rearing cages on a daily basis and typically used for tests on the day they were collected. If they could not be used the same day, eggs were stored at $10{ }^{\circ} \mathrm{C}$ for no longer than three days in order to prevent development. Since average egg mass sizes of $H$. halys and non-target species can vary significantly, for each test we standardized the egg mass size by separating egg masses into smaller clusters (10 eggs/ mass) and attaching them to $4 \mathrm{~cm}^{2}$ pieces of flat cardboard with small amount of clear glue (Cementit, merz + benteli Kolma AG, Wabern, Switzerland). In the case of Gonocerus acuteangulatus (Goeze), the eggs were left on the leaves they were laid on, and variable numbers of eggs (3-10) were used for testing since this species only lays single eggs in small clusters. Egg masses were then transferred into small $(5 \mathrm{~cm})$ Petri dishes.

In each experimental setup, similar numbers of randomly selected, naïve, mated $T$. japonicus females were tested simultaneously on egg masses of the target $H$. halys (control) and the non-target species listed in Table 1 (between 14 and 46 replicates per non-target species). Since daily offspring production of the synovigenic females peaks within the first week after emergence (Qui 2007), females were 4-7 days old when used for experiments. All wasps were fed with fresh honey water the morning before the experiments. Single T. japonicus females were added to each Petri 


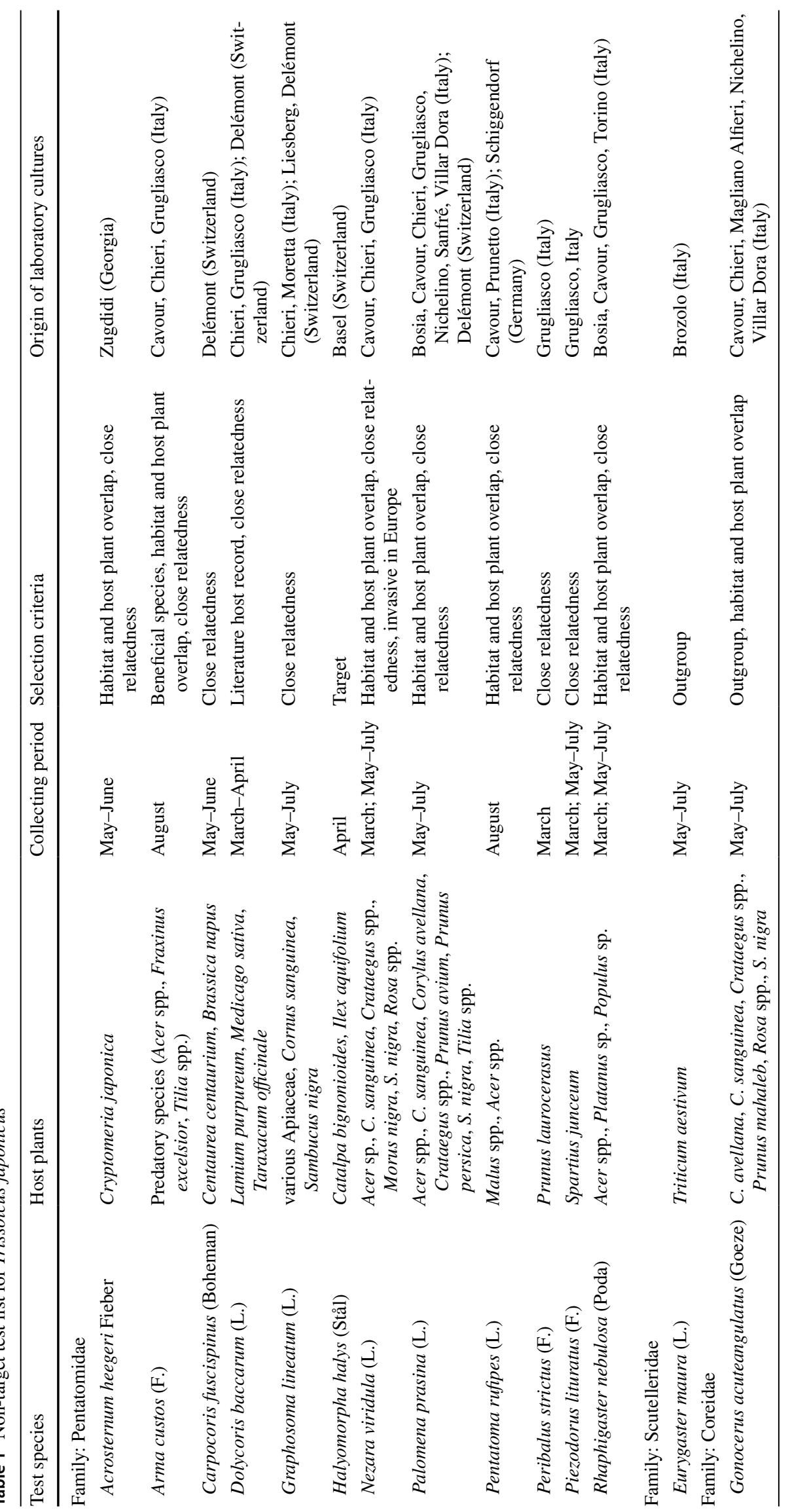


dish and observed under a stereomicroscope until they had at least one contact with the egg mass. If females had no interest in oviposition following the first contact, observations were continued for another $10 \mathrm{~min}$, and egg masses were counted as 'rejected' if no oviposition behaviour was observed. Females that started ovipositing were observed until they either had parasitized all 10 eggs, as indicated by marking behaviour ('acceptance'), or abandoned the partially parasitized egg mass for more than $10 \mathrm{~min}$.

The individual handling time of the egg masses was recorded for each $T$. japonicus female. All tests were conducted at $26 \pm 1{ }^{\circ} \mathrm{C}, 60-70 \% \mathrm{RH}$. In addition, unexposed controls of target and non-target egg masses were kept at the same conditions to evaluate baseline host mortality and to assess if T. japonicus females induced additional host mortality even in cases of failed development, a non-reproductive non-target effect, which is rarely considered explicitly in risk assessment of biological control agents (Abram et al. 2019b). After the tests, the wasps were removed, and both the non-target and $H$. halys egg masses were incubated under the above rearing conditions until emergence of stink bug nymphs and/or wasp adults ('host suitability'). The number of emerged parasitoids, nymphs and dead eggs (=no emergence) was recorded as well as the sex ratio of the parasitoid offspring. Finally, egg dissections were performed to determine whether any parasitoids or nymphs developed partially.

\section{Paired choice tests}

To evaluate target (H. halys) versus non-target parasitism under more realistic conditions than previous laboratory host range studies (Zhang et al. 2017; Hedstrom et al. 2017), large-arena choice tests were conducted (Van Lenteren et al. 2006) where individual T. japonicus females foraged on plants where bugs had fed and laid eggs. This procedure was followed because studies by Colazza et al. (2007, 2009) had shown that in a similar system, Trissolcus basalis (Wollaston) (Hymenoptera: Scelionidae) perceived chemical footprints left behind by its host Nezara viridula (L.) (Hemiptera: Pentatomidae) as contact kairomones, which induced foraging by gravid females. In addition, $T$. basalis also responded to synomones emitted by bean plants induced by feeding and oviposition activity of its host (Colazza et al. 2004).

The following four species were selected as representative hosts that were accepted frequently or less frequently in no-choice tests: Acrosternum heegeri Fieber, Ar. custos, Graphosoma lineatum (L.), and Palomena prasina (L.). In the case of H. halys, Pa. Prasina, and Ar. custos, potted broad bean plants (Vicia faba L., Fabaceae, about $20 \mathrm{~cm}$ high) were placed inside the stink bug rearing cages described above for $24 \mathrm{~h}$. Since Ac. heegeri and G. lineatum refused to lay eggs on broad bean plants, alternatively cut, fresh fruit-bearing branches of common ivy (H. helix) placed in a container with water were used instead. Accordingly, ivy branches were also offered to $H$. halys for oviposition to exclude potential effects of different host plants. After $24 \mathrm{~h}$, the plants were removed and inspected for egg masses. Plants carrying single egg masses were selected for testing. Since these five species lay egg masses of variable size, it was not possible to control for the number of eggs per plant. However, in this way the outcome of choice tests may represent parasitism in the field more realistically than no-choice tests, despite the nonstandardized egg masses.

Testing arenas consisted of fine gauze cages $(47.5 \times 47.5 \times 47.5 \mathrm{~cm})$, in which two plants were placed in the far left and right corners, each carrying a single egg mass of $H$. halys or non-target species, respectively. Plants did not touch the cage walls or each other. At the top of the cages, small drops of honey were placed in each corner as a food source for the parasitoids. Single, naïve, mated 4-7 days old T. japonicus females were removed from the rearing cage, and individually transferred into glass pipettes $(10 \mathrm{~cm}$ long, diameter $5 \mathrm{~mm}$ ) closed with a cotton wick. These tubes were then put into a small open plastic cup, which was placed in the middle of the front side of the cage, equidistant $(30 \mathrm{~cm})$ to the two test plants. The cotton wicks were removed, so the wasps could crawl up to the opening of the tubes and enter the test arena. All tests were conducted at $26 \pm 1{ }^{\circ} \mathrm{C}$, $60-70 \% \mathrm{RH}$, and a $16 \mathrm{~L} / 8 \mathrm{D}$ photoperiod. After $24 \mathrm{~h}$, the wasps were removed and both the $H$. halys and non-target egg masses were incubated under the above rearing conditions until emergence of stink bug nymphs and wasp adults. Each combination of target and non-target species was replicated between 19 and 40 times (Table 3).

\section{Statistical analysis}

In no-choice tests, acceptance (oviposition and marking behaviour), host suitability (mean offspring emergence per egg mass), and sex ratio (percentage female parasitoid offspring per host species) were compared pairwise between each non-target species and its respective $H$. halys control using generalized linear models (GLMs) with a binomial error distribution and a logit link function. Similarly, the host exploitation (number of eggs parasitized within an egg mass) and egg mass handling time were compared using a GLM with Poisson (log-link function) and gamma (inverse link function) error distributions, respectively. Replicates in which wasps did not parasitize all 10 eggs were excluded from the handling time analysis. The unattributed mortality ('dead eggs' $=$ no parasitoid emergence or dead parasitoids in dissected eggs, Table 2) of non-target eggs exposed to $T$. japonicus was compared pairwise with unattributed mortality in the respective rearing controls using a GLM with a quasibinomial error distribution (logit link function) to 
account for overdispersion. All GLMs were carried out with $\mathrm{R}$ version 3.2.3 (Team 2017) using the development environment RStudio (Team 2016).

For large-arena paired choice tests, the proportion of females parasitizing either target or non-target eggs were compared using a Pearson Chi-square test. The percentage of parasitoids emerging per parasitized egg mass was compared between species using a Wilcoxon's signed-rank test. Statistical tests were carried out with the SPSS ${ }^{\circledR} 20.0$ software package (IBM Corp. 2013).

\section{Results}

\section{No-choice tests}

Host acceptance In total, twelve out of thirteen non-target hosts were accepted by $T$. japonicus females (Table 2). The proportion of females accepting non-target egg masses, as indicated by oviposition behaviour and marking of eggs, was not significantly different for four non-target species, $P a$. prasina, Rhaphigaster nebulosa (Poda), Pentatoma rufipes (L.), and Ar. custos, than for the target host H. halys (Table 2, ESM 1). All other species were significantly less accepted. Gonocerus acuteangulatus, belonging to the outgroup family Coreidae, was the only species that was not accepted at all. The proportion of $T$. japonicus females accepting the target $H$. halys (controls) was generally high, ranging from $89 \%$ to $100 \%$ (average $96 \%$ ). The number of eggs parasitized within accepted egg masses (host exploitation) was $89 \%$ or higher for all accepted non-target species and not significantly different from $H$. halys controls (Table 2). The handling time (=time spent to parasitize an egg mass of 10 eggs) was significantly longer than in $H$. halys control when $T$. japonicus parasitized egg masses of Pa. prasina $(p \leq 0.05)$, and the less accepted species Dolycoris baccarum (L.), N. viridula, Peribalus strictus (F.), and G. lineatum $(p<0.001)$ (Table 2). The handling time was longest for the non-indigenous $N$. viridula (Table 2).

Host suitability Of the twelve non-target species accepted by $T$. japonicus, eleven were suitable for parasitoid development (Table 2). Levels of suitability (=proportion of parasitoids successfully emerging from parasitized eggs) were not significantly different for eight non-target species, $\mathrm{Pa}$. prasina, Carpocoris fuscispinus (Boheman), Pe. strictus, Ar. custos, D. baccarum, R. nebulosa, Ac. heegeri and E. maura, than for the target host $H$. halys. Suitability of the target $H$. halys (controls) was generally high, varying between $87 \%$ and $94 \%$ (average $92 \%$ ). Suitability of Pen. rufipes eggs (99\% emergence) was even higher than for the target host $H$. halys. For most non-target species, unattributed egg mortality ('dead eggs', Table 2) was higher in eggs masses exposed to $T$. japonicus than in the respective rearing controls (ESM
1). Particularly, egg mortality in G. lineatum and N. viridula increased due to parasitization from 14 and 54 (rearing controls) to 27 and $100 \%$, respectively (Table 2).

In general, for $H$. halys and all non-target species the sex ratio was female biased ( $>60 \%)$. However, parasitized eggs of Per. strictus $(61 \%)$ produced significantly fewer females than eggs of $H$. halys (Table 3 ).

\section{Paired choice tests}

The incubation of egg masses exposed in choice tests showed that some T. japonicus females were able to parasitize both egg masses within $24 \mathrm{~h}$, and thus, for these replicates it was not possible to state which host the parasitoid had chosen first. The number of females parasitizing both egg masses is given in Table 3, but these replicates were not included in the statistical analysis. Results of pairedchoice tests and no-choice tests were generally similar, and the four non-target test species were parasitized in both scenarios (Table 3). Egg masses of Ar. custos, G. lineatum and $A c$. heegeri were significantly less parasitized when paired with $H$. halys egg masses (Pearson Chi-square test, $p \leq 0.001$; Table 3; ESM 1), whereas levels of parasitism of Pa. prasina (47\%) were not significantly different than for the target $(53 \%)\left(\chi^{2}=0.267, p=0.606\right)$. The proportion of females that did not parasitize any egg mass within $24 \mathrm{~h}$ was low, ranging from 0 to $13 \%$. Percentages of emerging T. japonicus per parasitized non-target egg mass were not significantly different than for paired $H$. halys egg masses (Table 3, column 'emerged parasitoids').

\section{Discussion}

Developmental suitability of European non-target host species for T. japonicus was demonstrated by successful offspring emergence from eleven out of thirteen non-target species tested (85\%), which is consistent with the results of earlier host range studies in China $(7 / 8 ; 88 \%)$ and North America (7/10; 70\%) (Zhang et al. 2017; Hedstrom et al. 2017). Parasitoid emergence from successfully parasitized non-target eggs was generally high ( $>70 \%$ ), except for $G$. lineatum. Similar high emergence was observed for Asian non-target species (Zhang et al. 2017), whereas emergence from North American non-target species (and $H$. halys controls) was much lower (Hedstrom et al. 2017; Botch and Delfosse 2018). By relating parasitoid emergence directly to the observed oviposition behaviour and keeping unexposed rearing controls, we were able to demonstrate that $T$. japonicus caused non-reproductive parasitoid-induced mortality in G. lineatum (55.9\%) and the invasive $N$. viridula (100\%), the only non-indigenous species included in the test list. Since $H$. halys and $N$. 


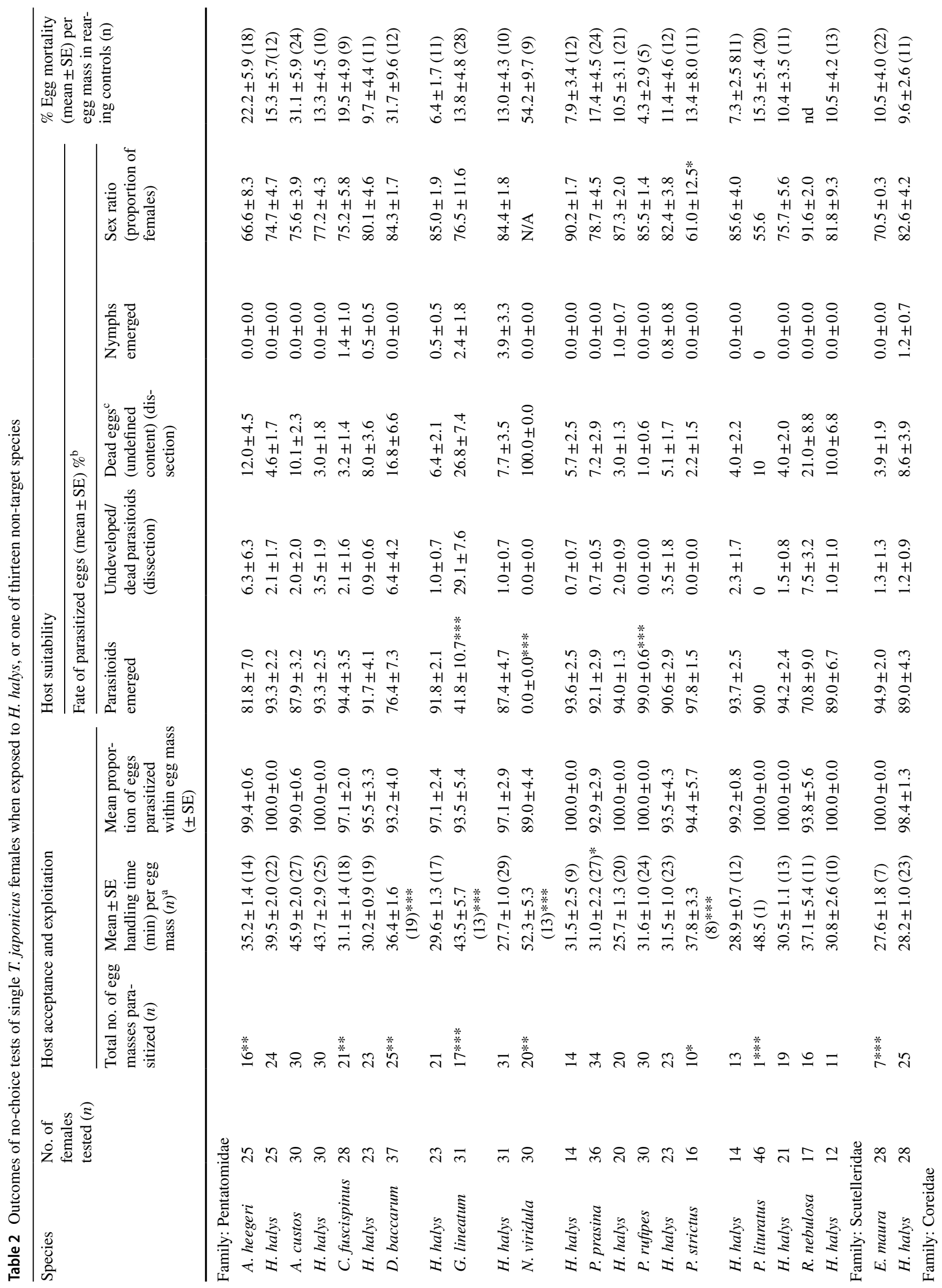




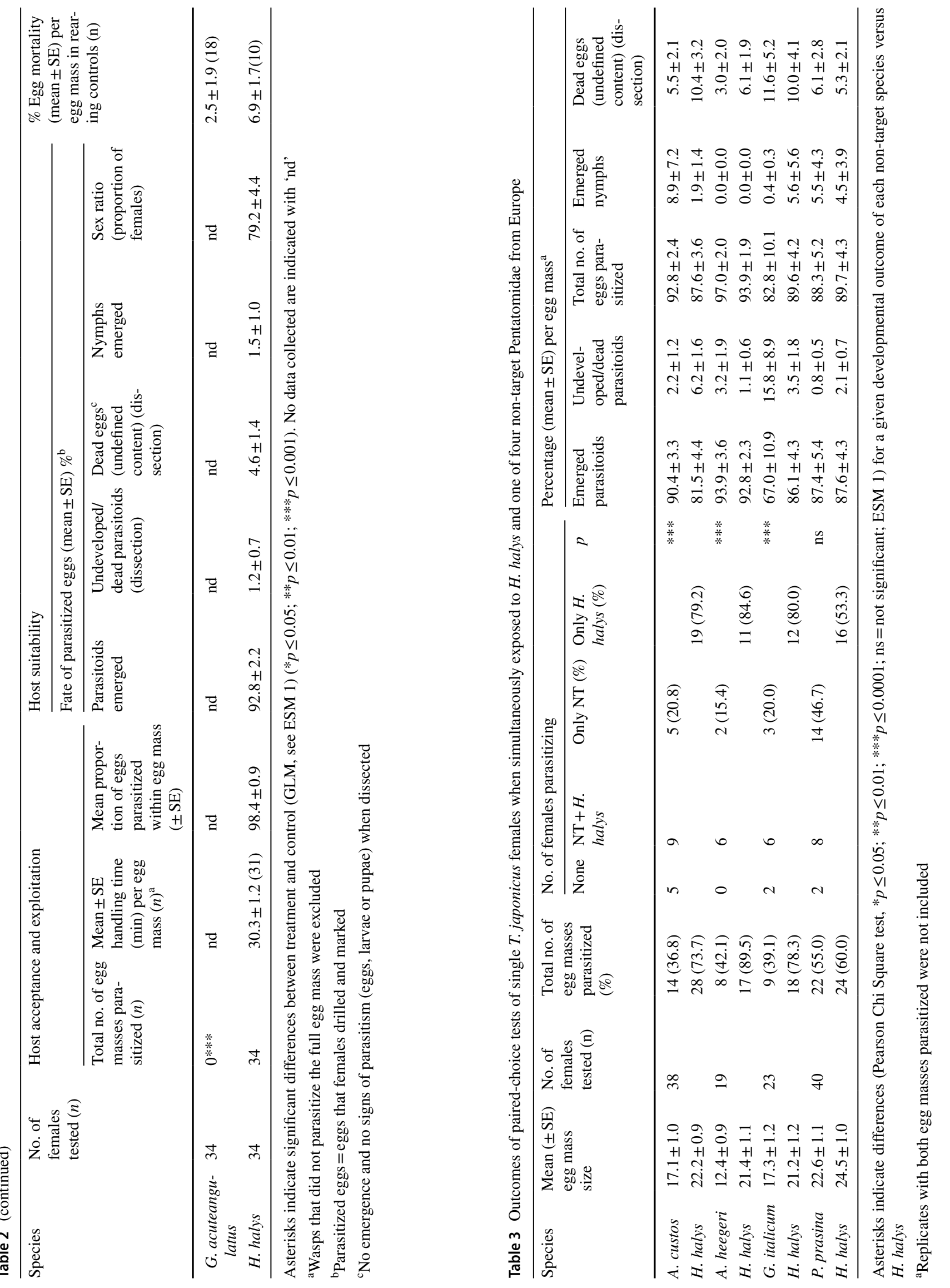


viridula often co-occur in the same crops, $T$. japonicus may have a positive non-target effect by contributing to the mortality of $N$. viridula eggs masses, which are often not fully exploited by $T$. basalis, one of the main egg parasitoids associated with N. viridula (Colazza and Bin 1995). However, the aggressive host guarding behaviour of $T$. japonicus could also exclude T. basalis from $N$. viridula egg masses, lowering the overall biological control of the pest. On the other hand, $N$. viridula could also operate as an 'evolutionary trap', because eggs were frequently accepted but not suitable for the development of $T$. japonicus (Abram et al. 2014). The unusually long handling time in no-choice tests may indicate that $N$. viridula eggs are less attractive for $T$. japonicus and it remains to be verified if T. japonicus indeed attacks $N$. viridula egg masses in the field.

Whereas most non-target species were significantly less attacked than the target host, acceptance of four suitable non-target species, Pa. prasina, Pen. rufipes, Ar. custos, and $R$. nebulosa, was not significantly different from $H$. halys controls. In Europe, these species mainly live on trees, resulting in habitat overlap with $H$. halys. Based on the outcome of the no-choice tests, these species could serve as alternative hosts for $T$. japonicus in the field and populationlevel impacts are more likely for these species than for any of the other tested non-targets.

Laboratory no-choice tests in simple structured arenas are usually the first step in risk assessment of biological control agents, providing conditions where the maximal fundamental host range is likely to be expressed (van Lenteren et al. 2006). Since non-targets were consistently attacked in nochoice tests, step large-arena choice tests were subsequently conducted to determine if non-targets are attacked when eggs of the target, $H$. halys, and non-target species are simultaneously present in a semi-natural situation on their host plants. Presenting eggs of Ar. custos, G. lineatum and Ac. heegeri in choice tests showed that introducing additional complexity (host plants with naturally laid eggs, feeding damage, and stink bug footprints) can reduce the degree of non-target host parasitism substantially, which agrees with studies by Hedstrom et al. (2017) and Botch and Delfosse (2018). Compared to small-arena choice tests, movement of $T$. japonicus from one egg mass to another within the testing period was reduced by using larger cages and adding more complexity. However, the emergence data showed that within $24 \mathrm{~h}$ some females were still able to parasitize both egg masses. After parasitizing the first egg mass, females would have been in a 'no-choice situation' when locating the second egg mass and we thus did not include these replicates. In a preliminary study, T. japonicus females guarded parasitized egg masses for at least $12 \mathrm{~h}$, and after $24 \mathrm{~h} 65 \%$ of females had left the egg masses (Haye, unpublished data). Accordingly, in future choice tests it would be advantageous to reduce the length of the testing period to $12 \mathrm{~h}$ or less; however, this would also increase the proportion of females that are not responsive in the given time.

Host range studies in Europe, China, and North America showed that some closely related, ecological equivalents (i.e., predatory species in the subfamily Asopinae) Ar. custos (Europe), Arma chinensis (Fallou) (China) and Podisus maculiventris (Say) (North America) are highly suitable hosts for T. japonicus. Since these species fall into the category of beneficial 'safeguard species' (Kuhlmann et al. 2006), potential non-target impacts would cause more concern than effects on other non-beneficial, herbivore stink bug species. However, the outcome of our choice tests suggests that the potential risk of substantial parasitism of Ar. custos might be much lower in the field than initially indicated by no-choice tests. In addition, experiments measuring fitness-related phenotypic parameters (e.g., size) of $T$. japonicus offspring emerging from $H$. halys eggs suggest that non-target host use, especially on predatory pentatomids with smaller eggs, may carry a significant fitness penalty for parasitoid offspring (Botch and Delfosse 2018).

In contrast to Ar. custos, parasitism of Pa. prasina eggs was not reduced in the presence of $H$. halys eggs. The reason why Ar. custos, but not Pa. prasina, was much less parasitized in choice tests is unknown. In a similar system, bean plants ( $V . f a b a)$ damaged by feeding activity of $N$. viridula, and onto which an egg mass had been laid, produced volatiles that attracted the egg parasitoid T. basalis (Colazza et al. 2004). Similarly, V. faba plants that were attacked by $H$. halys produced volatiles that were attractive for the native European egg parasitoids A. bifasciatus and O. telenomicida (Rondoni et al. 2017). Accordingly, it seems highly likely that feeding and oviposition of Pa. prasina on V. faba plants induced plant volatiles that were exploited by $T$. japonicus for host egg location. This may also explain why plants carrying eggs of the predatory species Ar. custos, which rarely feeds on plants, were less attractive for $T$. japonicus in largearena choice experiments.

In terms of ecological risk assessment, it remains unclear if there are behavioural barriers to parasitism, such as habitat preferences, competition with native egg parasitoids, or oviposition periods of non-target species, which may exist and inhibit parasitism of Pa. prasina, Pen. rufipes, and $R$. nebulosa in the field. For example, the oviposition period of the forest bug, Pen. rufipes, is starting from the end of August (Peusens and Beliën 2012) when the oviposition period (May-August) of $H$. halys ends (Costi et al. 2017). Little is known about the activity of $T$. japonicus before and after the oviposition period of $H$. halys in April and September, respectively. Further field studies are thus needed to clarify if in late summer Pen. rufipes escapes parasitism by T. japonicus or is attacked more frequently due to larger population size 
of $T$. japonicus and the limited availability of $H$. halys eggs. Similarly, $R$. nebulosa is one of the first species to become active in spring, and it remains unknown if $T$. japonicus could use this species as an alternative host in April before $H$. halys eggs are present in the field. Factors such as habitat associations, host location, life cycle synchrony, and searching capacity of parasitoids are not easily reproduced in laboratory tests (Cameron et al. 2013) and some uncertainty may remain even after more complex host range testing. This is aggravated by the fact that there is often a lack of knowledge on the phenology and ecology of the non-target species themselves.

Regardless of the future impact on non-target species in the field, the arrival of T. japonicus in Europe is now irreversible, and bioclimatic envelope models (Avila and Charles 2018) suggest that it will spread throughout Europe, following the invasion routes of its primary host, $H$. halys. Ecological host range studies in China (Zhang et al. 2017) suggest that 'host use' (minor use of a non-target species for reproduction) of some European non-target species is a likely scenario, but on the other hand this may also increase the chances of establishment and survival of T. japonicus populations. Field data from the invaded areas in Switzerland and Italy may help to determine if the re-location of $T$. japonicus into other areas in Europe affected by $H$. halys poses any additional risk and could contribute to a risk-benefit evaluation of releases of $T$. japonicus.

In the USA, where adventive populations of $T$. japonicus were first discovered in 2014 (Talamas et al. 2015), the wasps are currently being relocated and released in agricultural locations within state boundaries where $T$. japonicus has spread naturally (Jentsch 2017). Studies of non-target parasitism in the field are ongoing, but to our best knowledge severe non-target parasitism has not yet been observed. Based on a risk-benefit analysis considering scientific data, economic analysis, contemporary evidence, and cultural and broader social impacts, an application for release of $T$. japonicus was recently approved (with controls) in New Zealand to support an eradication programme in the event of a $H$. halys incursion (https://www.epa.govt.nz). Following the New Zealand example, a risk-benefit analysis could help European countries affected by $H$. halys to decide if releases of $T$. japonicus are justified. In response to $H$. halys outbreaks, the use of broad-spectrum insecticides, especially pyrethroids, has increased greatly in the USA and Italy, which has disrupted existing integrated pest management programmes and caused outbreaks of secondary pests (Leskey and Nielsen 2018). Therefore, bearing in mind the worldwide decline of the entomofauna, some of which may be linked to the use of insecticides (Sánchez-Bayoa and Wyckhuys 2019), the small risk of potential non-target effects on some native stink bug species, in comparison with the environmental risks of continuous use of insecticides, should be considered when evaluating the option of re-locating and releasing T. japonicus in Europe.

\section{Author contribution statement}

TH, LT, TG conceived and designed research. TH and JS conducted experiments and analysed data. TH wrote the manuscript. STM and SV collected and reared non-target species for establishing laboratory colonies. All authors read and approved the manuscript.

Acknowledgements The research was carried out with the cooperation and contribution of the Hazelnut company division of the Ferrero Group. We would like to thank Chelsey Blackman, Darren Blackburn, Taylor Kaye, Jessica Fraser, Lindsay Craig, Christie Laing, Anna Grunsky, Mariah Ediger for technical assistance in the laboratory, and Lara Bosco, Gabriele Castelli, Marco G. Pansa for their help in bug collection. We like to thank Paul Abram for constructive comments on an earlier version of the manuscript. CABI is an international intergovernmental organisation, and we gratefully acknowledge the core financial support from our member countries (and lead agencies) including the United Kingdom (Department for International Development), China (Chinese Ministry of Agriculture), Australia (Australian Centre for International Agricultural Research), Canada (Agriculture and AgriFood Canada), Netherlands (Directorate-General for International Cooperation), and Switzerland (Swiss Agency for Development and Cooperation). See http://www.cabi.org/about-cabi/who-we-work-with/ key-donors/ for full details.

\section{Compliance with ethical standards}

Conflict of interest The authors declared that they have no conflict of interest.

Informed consent Informed consent was obtained from all individual participants included in the study.

Research involving human participants and/or animals This article does not contain any studies with human participants or animals (vertebrates) performed by any of the authors.

Open Access This article is distributed under the terms of the Creative Commons Attribution 4.0 International License (http://creativeco mmons.org/licenses/by/4.0/), which permits unrestricted use, distribution, and reproduction in any medium, provided you give appropriate credit to the original author(s) and the source, provide a link to the Creative Commons license, and indicate if changes were made.

\section{References}

Abram PK, Gariepy TD, Boivin G, Brodeur J (2014) An invasive stink bug as an evolutionary trap for an indigenous egg parasitoid. Biol Invasions 16:1387-1395

Abram PK, Brodeur J, Burte V, Boivin G (2016) Parasitoid-induced host egg abortion: an underappreciated component of biological control services provided by egg parasitoids. Biol Control 98:52-60 
Abram PK, Hoelmer KA, Acebes-Doria A et al (2017) Indigenous arthropod natural enemies of the invasive brown marmorated stink bug in North America and Europe. J Pest Sci 90:1009-1020

Abram PK, Talamas EJ, Acheampong S, Mason PG, Gariepy TD (2019a) First detection of the samurai wasp, Trissolcus japonicus (Ashmead) in Canada. J Hymenopt Res 68:29-36

Abram PK, Brodeur J, Urbaneja A, Tena A (2019b) Non reproductive effects of insect parasitoids on their hosts. Annu Rev Entomol 64:259-276

Avila GA, Charles JG (2018) Modelling the potential geographic distribution of Trissolcus japonicus: a biological control agent of the brown marmorated stink bug, Halyomorpha halys. Biocontrol 63:505-518

Bosco L, Moraglio ST, Tavella L (2018) Halyomorpha halys, a serious threat for hazelnut in newly invaded areas. J Pest Sci 91:661-670

Botch PS, Delfosse ES (2018) Host-acceptance behavior of Trissolcus japonicus (Hymenoptera: Scelionidae) reared on the invasive Halyomorpha halys (Heteroptera: Pentatomidae) and nontarget species. Environ Entomol 47:403-411

Cameron PJ, Hill RL, Teulon DAJ, Stukens MAW, Connolly PG, Walker GP (2013) A retrospective evaluation of the host range of four Aphidius species introduced to New Zealand for the biological control of pest aphids. Biol Control 67:275-283

Claerebout S, Haye T, Ólafsson E, Pannier E, Bultot J (2018) Première occurrence de Halyomorpha halys (Stål, 1855) (Hemiptera: Heteroptera: Pentatomidae) pour la Belgique et actualisation de sa distribution en Europe. Bull Soc R Belg Entomol 154:205-227

Colazza S, Bin F (1995) Efficiency of Trissolcus basalis (Hymenoptera: Scelionidae) as an egg parasitoid of Nezara viridula (Heteroptera: Pentatomidae) in central Italy. Environ Entomol 24:1703-1707

Colazza S, Fucarino A, Peri E, Salerno G, Conti E, Bin F (2004) Insect oviposition induces volatile emission in herbaceous plants that attracts egg parasitoids. J Exp Biol 207:47-53

Colazza S, Aquila G, De Pasquale C, Peri E, Millar JG (2007) The egg parasitoid Trissolcus basalis uses n-nonadecane, a cuticular hydrocarbon from its stink bug host Nezara viridula, to discriminate between female and male hosts. J Chem Ecol 33:1405-1420

Colazza S, Lo Bue M, Lo Giudice D, Peri E (2009) The response of Trissolcus basalis to footprint contact kairomones from Nezara viridula females is mediated by leaf epicuticular waxes. Naturwissenschaften 96:975-981

Costi E, Haye T, Maistrello L (2017) Biological parameters of the invasive brown marmorated stink bug, Halyomorpha halys, in southern Europe. J Pest Sci 90:1059-1067

Costi E, Haye T, Maistrello L (2018) Surveying native egg parasitoids and predators of the invasive Halyomorpha halys in Northern Italy. J Appl Entomol 143:299-307

Derjanschi V, Péricart J (2005) Hémiptères Pentatomoidea, vol 1. Faune de France 90, Fédération Française des Sociétés de Sciences Naturelles, Paris

Haye T, Gariepy TD, Hoelmer K, Rossi J-P, Streito J-C, Tassus T, Desneux N (2015a) Range expansion of the invasive brown marmorated stinkbug, Halyomorpha halys: an increasing threat to field, fruit and vegetable crops worldwide. J Pest Sci 88:665-673

Haye T, Fischer S, Zhang J, Gariepy T (2015b) Can native egg parasitoids adopt the invasive brown marmorated stink bug, Halyomorpha halys (Heteroptera: Pentatomidae), in Europe? J Pest Sci 88:693-705

Hedstrom C, Lowenstein D, Andrews H, Bai B, Wiman N (2017) Pentatomid host suitability and the discovery of introduced populations of Trissolcus japonicus in Oregon. J Pest Sci 90:1169-1179

Heimpel GE, Mills N (2017) Biological control: ecology and applications. Cambridge University Press, Cambridge

Hoebeke ER, Carter ME (2003) Halyomorpha halys (Stál) (Heteroptera: Pentatomidae): a polyphagous plant pest from Asia newly detected in North America. Proc Entomol Soc Wash 105:225-237
Hunt E, Kuhlmann U, Sheppard A, Qin TK, Barratt BIP, Harrison L, Mason PG, Parker D, Flanders RV, Goolsby J (2008) Review of invertebrate biological control regulation in Australia, New Zealand, Canada and the USA: recommendations for a harmonized European system. J Appl Entomol 132:89-123

Jentsch P (2017) Expanding the Range of the Samurai Wasp, Trissolcus japonicus, in New York Orchards. http://nyshs.org/wp-conte nt/uploads/2018/04/Jentsch-Pages-31-36-from-NYFQ-Winte r-Book-2017.pdf. Accessed 14 Feb 2019

Kriticos D, Kean J, Phillips C, Senay S, Acosta H, Haye T (2017) The potential global distribution of the brown marmorated stink bug, Halyomorpha halys Stål (Hemiptera: Pentatomidae): a critical threat to plant biosecurity. J Pest Sci 90:1033-1043

Kuhlmann U, Schaffner U, Mason PG (2006) Selection of non-target species for host specificity tests. In: Bigler F, Babendreier D, Kuhlmann U (eds) Biological control of arthropods using invertebrates: methods for environmental risk assessment. CABI Publishers, Wallingford, pp 15-37

Lee DH, Short BD, Joseph SV, Bergh JC, Leskey TC (2013) Review of the biology, ecology, and management of Halyomorpha halys (Hemiptera: Pentatomidae) in China, Japan, and the Republic of Korea. Environ Entomol 42:627-641

Leskey TC, Nielsen AL (2018) Impact of the invasive brown marmorated stink bug in North America and Europe: history, biology, ecology, and management. Annu Rev Entomol 63:599-618

Maistrello L, Vaccari G, Caruso S et al (2017) Monitoring of the invasive Halyomorpha halys, a new key pest of fruit orchards in northern Italy. J Pest Sci 90:1231-1244

Milnes JM, Wiman NG, Talamas EJ et al (2016) Discovery of an exotic egg parasitoid of the brown marmorated stink bug, Halyomorpha halys (Stål) in the Pacific Northwest. Proc Entomol Soc Wash 118:466-470

Moulet P (1995) Hémiptères Coreoidea euro-méditerranéens. Faune de France 81, Fédération Française des Sociétés de Sciences Naturelles, Paris

Peusens G, Beliën T (2012) Life cycle and control of the forest bug Pentatoma rufipes L. in organically managed pear orchards. Commun Agric Appl Biol Sci 77:663-666

Qui LF (2007) Studies on biology of the brown marmorated stink bug Halyomorpha halys (Stål) (Hemiptera: Pentatomidae), an important pest for pome trees in China and its biological control. Ph.D. dissertation, Chinese Academy of Forestry, Beijing, China

R Core Team (2017) R: a language and environment for statistical computing. R Foundation for Statistical Computing, Vienna. https ://www.R-project.org/. Accessed 15 Feb 2019

R Studio Team (2016) R Studio: integrated development for R. RStudio, Inc., Boston. http://www.rstudio.com/. Accessed 15 Feb 2019

Rondoni G, Bertoldi V, Malek R, Foti MC, Peri E, Maistrello L, Haye T, Conti E (2017) Native egg parasitoids recorded from invasive Halyomorpha halys exploit volatiles emitted by the plant-herbivore complex. J Pest Sci 90:1087-1095

Roversi PF, Marianelli L, Costi E, Maistrello L, Sabbatini PG (2016) Searching for native egg-parasitoids of the invasive alien species Halyomorpha halys Stål (Heteroptera Pentatomidae) in Southern Europe. Redia 99:63-70

Sabbatini Peverieri G, Talamas E, Bon MC, Marianelli L, Bernardinelli I, Malossini G, Benvenuto L, Roversi PF, Hoelmer K (2018) Two Asian egg parasitoids of Halyomorpha halys (Stål) (Hemiptera, Pentatomidae) emerge in northern Italy: Trissolcus mitsukurii (Ashmead) and Trissolcus japonicus (Ashmead) (Hymenoptera, Scelionidae). J Hymenopt Res 67:37-53

Sánchez-Bayoa F, Wyckhuys KAG (2019) Worldwide decline of the entomofauna: a review of its drivers. Biol Conserv 232:8-27

Stahl J, Tortorici F, Pontini M, Bon MC, Hoelmer K, Marazzi C, Tavella L, Haye T (2018) First discovery of adventive 
populations of Trissolcus japonicus in Europe. J Pest Sci. https:// doi.org/10.1007/s10340-018-1061-2

Talamas EJ, Herlihy MV, Dieckhoff C, Hoelmer KA, Buffington M, Bon MC, Weber DC (2015) Trissolcus japonicus (Ashmead) (Hymenoptera, Scelionidae) emerges in North America. J Hymenopt Res 43:119-128

van Lenteren JC, Bale J, Bigler F, Hokkanen HMT, Loomans AJM (2006) Assessing risks of releasing exotic biological control agents of arthropods pests. Ann Rev Entomol 51:609-634

Wyniger D, Kment P (2010) Key for the separation of Halyomorpha halys (Stål) from similar-appearing pentatomids (Insecta: Heteroptera: Pentatomidae) occurring in Central Europe, with new Swiss records. Mitt Schweiz Entomol Ges 83:261-270
Yang Z-Q, Yao Y-X, Qiu L-F, Li Z-X (2009) A new species of Trissolcus (Hymenoptera: Scelionidae) parasitizing eggs of Halyomorpha halys (Heteroptera: Pentatomidae) in China with comments on its biology. Ann Entomol Soc Am 102:39-47

Zhang J, Zhang F, Gariepy T, Mason P, Gillespie D, Talamas E, Haye $\mathrm{T}$ (2017) Seasonal parasitism and host specificity of Trissolcus japonicus in northern China. J Pest Sci 90:1127-1141

Publisher's Note Springer Nature remains neutral with regard to jurisdictional claims in published maps and institutional affiliations. 